\title{
How deep to dig?
}

\section{Breed ${ }^{1}$}

Published online: 16 April 2018

(c) International Union for the Study of Social Insects (IUSSI) 2018
In an intriguing paper in this issue of Insectes Sociaux, Römer (2018) and her colleagues ask: How do leaf-cutting ants, when constructing their nest, respond to carbon dioxide levels? Leafcutters in the genus Acromyrmex farm fungi, so for these ants maintaining homeostasis involves regulating conditions for both the ants and their crop of fungi.

$\mathrm{CO}_{2}$ is ubiquitous, benign to most animals at atmospheric concentrations, and, potentially lethal at higher concentrations. Photosynthetic organisms require $\mathrm{CO}_{2}$ as the basis for building sugars, and heterotrophs release $\mathrm{CO}_{2}$ into their surroundings as a metabolic product. Unventilated areas, such as nests of social insects, can accumulate levels of $\mathrm{CO}_{2}$ that may become lethal. In response to the buildup of metabolic by-products in nests- $\mathrm{CO}_{2}$, water, and heat-many social insects have elaborate architectural systems to enhance air circulation and regulate concentrations of these by-products as well as ensuring a supply of oxygen to support metabolism (Ocko et al. 2017).

Social insect architecture, however, does not result from following a design like an architectural drawing. Instead, each worker makes a decision about its construction work based on information it gathers from its immediate surroundings. The resulting structure is the compounded result of thousands of minute responses. Differences in these simple response patterns among species result in dramatic interspecific variation in nest architectures. The evolution of nest architecture is a fascinating area of study in social insect biology and it is safe to say that we have only the beginning of an understanding of the processes and evolutionary tradeoffs that guide nest construction.

$\mathrm{CO}_{2}$ is a particular problem for tunneling animals, and ants are capable of detecting $\mathrm{CO}_{2}$ levels in their environment using sensillae on their antennae. This ability, while not unique to ants among the insects, is well developed in

M. Breed

michael.breed@colorado.edu

1 Department of Ecology and Evolutionary Biology, The University of Colorado, Boulder, Boulder, CO 80309-0334, USA ants, and is an unsurprising feature as they may encounter high $\mathrm{CO}_{2}$ in subterranean nests. Ants could respond to high $\mathrm{CO}_{2}$ levels either by avoiding nest construction where $\mathrm{CO}_{2}$ is elevated or by constructing ventilation turrets that facilitate air exchange.

The question of response to $\mathrm{CO}_{2}$ concentrations in leafcutting ants is complicated by their need to ensure not only their own survival, but also the survival of their fungal garden. High levels of $\mathrm{CO}_{2}$ inhibit fungal growth, potentially feeding back to diminished colony productivity for the ants. $\mathrm{CO}_{2}$ levels in soils tend to be higher, by two or three orders of magnitude, than atmospheric concentrations, and increase with depth below the soil surface. It would be reasonable to hypothesize that ants would seek to construct nest chambers at depths that optimize $\mathrm{CO}_{2}$ concentrations. However, there may be significant trade-offs in terms of soil temperature and moisture that cause ants to choose a compromise nest chamber depth that balances $\mathrm{CO}_{2}$, temperature and moisture.

Römer et al. (2018) test the excavation behavior of Acromyrmex lundii ants at ranges of atmospheric $\mathrm{CO}_{2}$ concentrations up to $11 \%$. They used two experimental designs; one captured the dependence of digging rate and soil removal rate on $\mathrm{CO}_{2}$ concentration and the other assessed choices of digging areas based on $\mathrm{CO}_{2}$ concentration. This species differs from many other Attines in building its nest chambers close to the soil surface.

Digging rate was not affected by $\mathrm{CO}_{2}$ concentration except for inhibition at the highest level, $11 \%$, a level that would not be expected in soil layers where leafcutters excavate their nests. Soil removal, on the other hand, increased with rising $\mathrm{CO}_{2}$ levels up to $7 \%$, and then showed an inhibitory decline at $11 \%$. Digging choices suggested a preference for excavation in soils with $\mathrm{CO}_{2}$ concentrations that favor fungal growth.

These results offer an explanation for this species' nest chambers near the soil surface- that the ants select locations that offer conducive $\mathrm{CO}_{2}$ growth conditions for their brood and fungi. Other ant species place chambers much deeper in the soil, where they encounter higher $\mathrm{CO}_{2}$ levels, but more 
constant temperature and humidity and they may respond by building effective ventilation systems.

This paper is exciting because it applies a careful experimental analysis to the trade-offs involved in nest construction. While the behavior of individual ants was not tracked, the group responses to $\mathrm{CO}_{2}$ help us to understand the dynamics that must be happening at the level of the individual ant. The fact that not all ant species come to the same solution for nest fabrication optimality reflects the subtlety of the evolutionary process and helps us to appreciate the complexity of architecture built on very simple individual rubrics.

\section{References}

Ocko SA, King H, Andreen D, Bardunias P, Turner JS, Soar R, Mahadevan L (2017) Solar-powered ventilation of African termite mounds. J Exp Biol 220:3260-3269. https://doi.org/10.1242/ jeb. 160895

Römer D, Halboth F, Bollazzi M, Roces F (2018) Underground nest building: the effect of $\mathrm{CO}_{2}$ on digging rates, soil transport and choice of a digging site in leaf-cutting ants. Insectes Soc. https:// doi.org/10.1007/s00040-018-0615-x

Michael Breed

Editor-in-Chief 